\title{
An escape from response to long-term pasireotide treatment in recurrent Cushing's disease
}

\author{
Gabalec F. ${ }^{1}$, Hušek P. ${ }^{2}$, Pacovský J. ${ }^{2}$, Čáp J. ${ }^{1}$ \\ ${ }^{14}$ th Dept. Of Internal Medicine, ${ }^{2}$ Dept. Of Urology University Hospital in Hradec Kralove \\ and Charles University, Faculty of Medicine in Hradec Kralove, Czech Republic
}

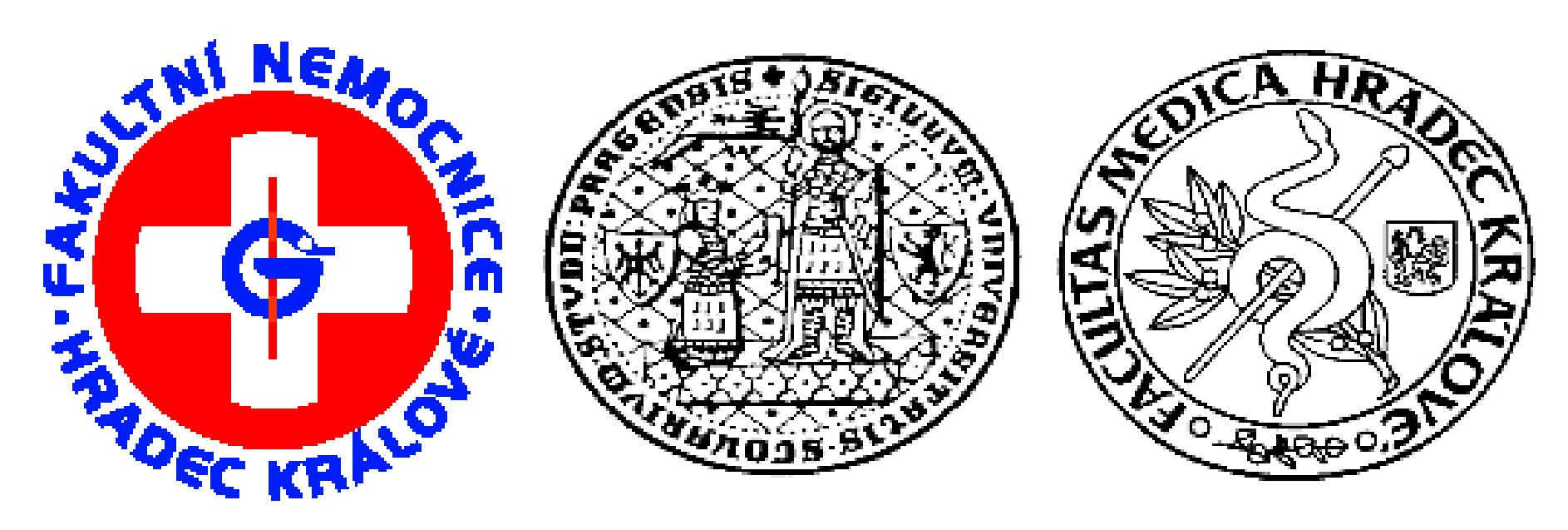

\section{Introduction}

A transsphenoidal adenectomy (TSFE) is primary treatment of Cushing's disease. (CD) Pharmacological management when the disease persists after surgery is a challenge.

\section{Case presentation}

47-year-old man was initially diagnosed with CD (petrosal sinus sampling with $\mathrm{CRH}$ testing included) after suffering from multiple organ failure in sepsis. Microadenoma 2x4 mm was suspected on the pituitary MRI. Clinical symptoms were markedly improved after first TSFE, but normalization was not achieved, so he underwent reoperation. No adenoma was present on control MRI, but CD remained active. Ketoconazole was no longer available so treatment with cabergoline according to national guidelines had started. Because no effect was observed, we started treatment with pasireotide $0.6 \mathrm{mg}$ bid. In 2 month this treatment led to normalization of UFC ( $208 \mathrm{nmol} / 24 \mathrm{~h}$ ), plasma cortisol in normal range, ACTH $49 \mathrm{pg} / \mathrm{ml}$. Mild elevation of glyHb was observed (from 5.6 to $8.0 \ldots 6.6 \ldots 6.3$ ), but diabetes was under control with oral antihyperglycemic agents.

Patient was doing well, reporting better quality of life and physical condition. Unfortunately 16 month after pasireotide introduction he was admitted for diabetes decompensation (glycaemia $37 \mathrm{mmol} / \mathrm{l}$ ) and bad condition for symptomatic CD (plasma cortisol > $2000 \mathrm{mmol} / \mathrm{l}$, ACTH 321 $\mathrm{pg} / \mathrm{ml}$, UFC $12240 \mathrm{nmol} / 24 \mathrm{~h}$ ). Pasireotide was discontinued, treatment with insulin was started. For fast deteriorating of his clinical status due to active $C D$ he was indicated to laparoscopic bilateral adrenalectomy as "ultimum refugium". The patient is now dispensarized for eventual Nelson's syndrome.
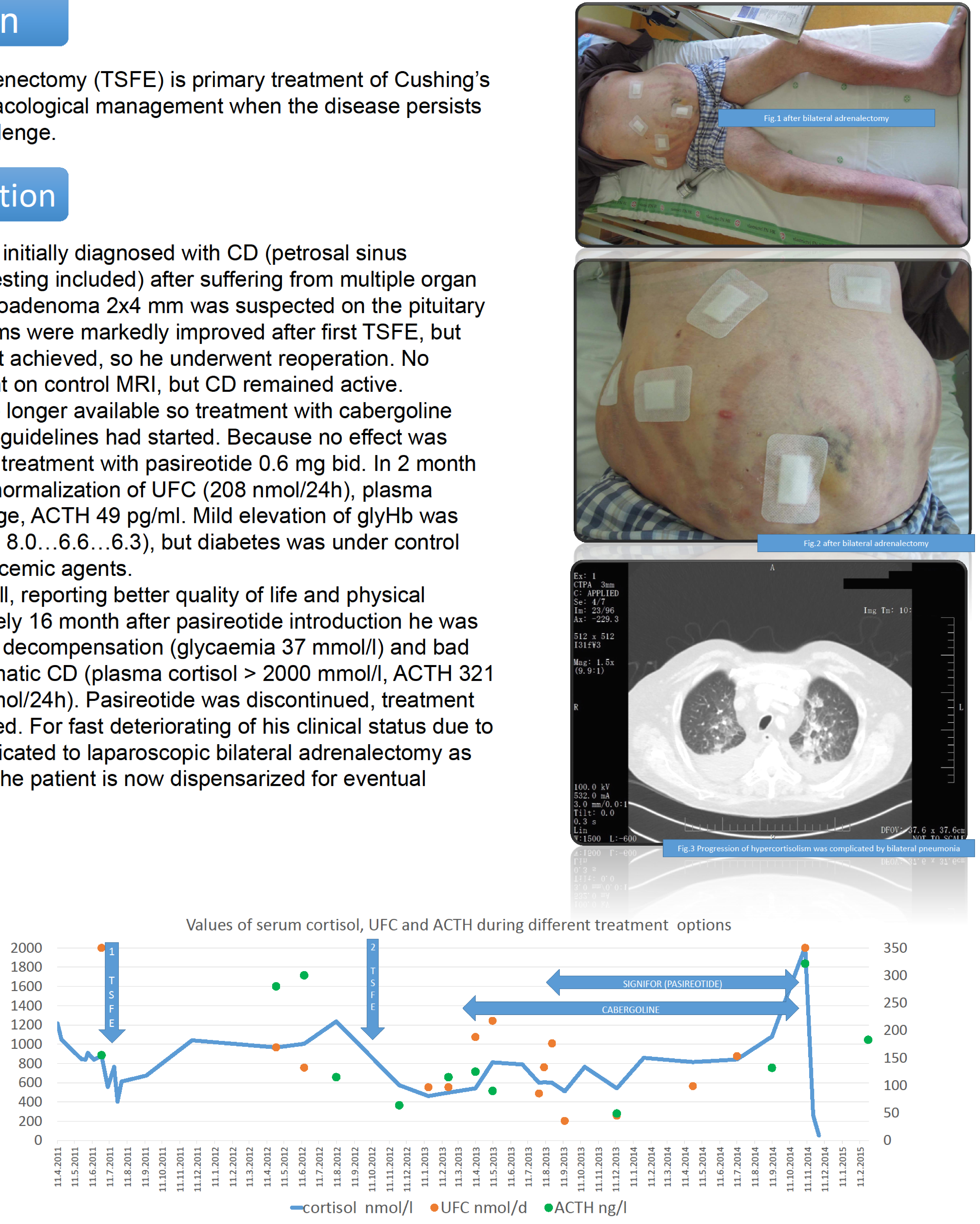

Mild hyperglycaemia at the start of pasireotide is not the reason for discontinuation. This case reports lack of efficacy of pasireotide after long-term effective treatment. 